\title{
Chryseobacterium indologenes infection in a newborn: a case report
}

\author{
Gema Calderón*, Esther García, Pilar Rojas, Elisa García, Marisa Rosso, Antonio Losada
}

\begin{abstract}
Introduction: Chryseobacterium indologenes is an uncommon human pathogen. Most infections have been detected in hospitalized patients with severe underlying diseases who had indwelling devices implanted. Infection caused by $C$. indologenes in a newborn has not been previously reported.

Case presentation: We present a case of ventilator-associated pneumonia caused by $C$. indologenes in a full-term Caucasian newborn baby boy with congenital heart disease who was successfully treated with piperacillin-tazobactam.

Conclusion: $C$. indologenes should be considered as a potential pathogen in newborns in the presence of invasive equipment or treatment with long-term broad-spectrum antibiotics. Appropriate choice of effective antimicrobial agents for treatment is difficult because of the unpredictability and breadth of antimicrobial resistance of these organisms, which often involves resistance to many of the antibiotics chosen empirically for serious Gram-negative infections.
\end{abstract}

\section{Introduction}

Chryseobacterium spp. are Gram-negative bacilli widely distributed in soil and water. In hospital environments, they have been recovered from water systems and humid surfaces. Infections caused by Chryseobacterium indologenes are rare, but have been reported as a cause of serious infections in adult immunosuppressed patients. To the best of our knowledge, infection caused by $C$. indologenes in a newborn has not been previously reported.

\section{Case presentation}

Our patient, a full-term Caucasian newborn baby boy with congenital heart disease (double-outlet right ventricle, mitral atresia and hypoplastic aortic arch) remained intubated and under mechanical ventilation from the seventh day of life due to hemodynamic deterioration. Then, 20 days later, he deteriorated clinically with worsening fever, intense leukocytosis, increase of acute-phase reactants and pulmonary infiltrate on chest radiograph. Empiric antibiotic therapy with meropenem and vancomycin was given. Bacteriological blood, cerebrospinal fluid and urine culture test results were negative.

\footnotetext{
* Correspondence: gmcalderonl@terra.es

Neonatology Unit, 'Virgen del Rocío' University Children's Hospital, Seville, Spain
}

\section{Biomed Central}

C. indologenes was isolated from a tracheobronchial secretion sample obtained by endotracheal aspiration. Treatment was discontinued at 10 days on clinical improvement. Then, five days later, he again developed fever and pulmonary infiltrate on chest radiograph. C. indologenes was again isolated from respiratory samples obtained by bronchoalveolar lavage (BAL). No other microorganisms were isolated from the BAL sample. The bacteria were susceptible in vitro to fluoroquinolones, cefepime, piperacillin-tazobactam and co-trimoxazole with intermediate susceptibility to third-generation cephalosporins; it was resistant to meropenem, imipenem, aztreonam, sulbactam-ampicillin and aminoglycosides. Antibiotic therapy with piperacillin-tazobactam was given and continued for 14 days. Our patient continued to do well up to the time of surgery for the repair of the congenital heart disease two months later.

\section{Discussion}

The genus Chryseobacterium belongs to the family Flavobacteriaceae. Six species of Chryseobacterium are more commonly isolated from clinical specimens: $C$. meningosepticum, C. odoratum, C. multivorum, C. breve and group IIb Chryseobacterium spp., which includes $C$. indologenes and C. gleum. Chryseobacterium spp. are Gram-negative, aerobic, non-fermentative, oxidase-positive and catalase-positive 
non-motile bacilli that produce a distinct yellow to orange pigment [1]. They are widely distributed in nature and found primarily in soil and water. They are not normally present in the human microflora [1,2]. They can survive in chlorinated waters, and in the hospital environment they exist in water systems and wet surfaces and serve as potential reservoirs of infection. Colonization of patients via contaminated medical devices such as respirators, endotracheal and tracheostomy tubes, humidifiers, incubators for newborns and syringes has been documented previously $[2,3]$. Contaminated surgically implanted devices such as intravascular catheters and prosthetic valves have also been reported [4]. Chryseobacterium infections in humans are usually acquired nosocomially and are frequently associated with the presence of invasive equipment (intra-vascular catheters, endotracheal tubes, prosthetic device) in immunocompromised patients or patients who have received long-term broad-spectrum antibiotics [4,5]. C. meningosepticum is the most pathogenic member of the genus; it is an agent of neonatal meningitis with mortality rates of up to $57 \%$ and is involved to a lesser extent in cases of pneumonia and bacterial sepsis in neonates and adults [6] C. indologenes is an uncommon human pathogen. The clinical significance of $C$. indologenes has not been fully established yet because this bacterium has not been frequently recovered from clinical specimens. Reported infections include bacteriemia, ventilator-associated pneumonia, indwelling device-associated infection, pyonephritis, biliary tract infection, peritonitis, lumboperitoneal shunt infection, ocular infections, and surgical and burn wound infections, and infection has been associated with a high mortality rate [4,5,7-13].

In the literature we have found six cases published of infections for C. indologenes in children; all of the patients were older than three months of age [9-13]. Hsueh et al. $[9,10]$ reported three pediatric cases of C. indologenes bacteremia. The first two patients were a one-year-old girl and a five-year-old girl, both receiving chemotherapy for a neoplastic disease and both with indwelling central venous catheters. The third patient was a one-year-old boy with a burn injury who was under mechanical ventilation. The one-year-old boy with burns developed an adult respiratory syndrome and died despite antimicrobial treatment; the other two patients recovered after three days of treatment. Cascio et al. [11] reported on a two-year-old boy with type 1 diabetes mellitus who developed bacteremia. The only medical device present was a peripheral catheter. The patient received antimicrobial treatment with ceftriaxone and recovered after two days.

In 2007, Bayraktar et al. [12] reported on a bloodstream infection in a five-month-old baby. Molecular typing with arbitrarily primed polymerase chain reaction demonstrated the cross-contamination of commercial distillate water. The baby was infected by this water as a result of medical assistance received during hospitalization.

Al-Tatari et al. [13] reported on a lumboperitoneal shunt infection in a 13-year-old boy with congenital hydrocephalus successfully treated with trimethoprimsulfamethoxazole and rifampim.

To the best of our knowledge, our patient's case is the first reported example of infection caused by C. indologenes in a newborn. Appropriate choice of effective antimicrobial agents for treatment of infection by $C$. indologenes is difficult because of the unpredictability and breadth of antimicrobial resistance of these organisms, which often involves resistance to many of the antibiotics chosen empirically for serious Gram-negative infections.

C. indologenes is often resistant to extended-spectrum penicillins, first-generation and second-generation cephalosporins, ceftriaxone, aztreonam, ticarcillin-clavulanate, chloramphenicol, erythromycin, aminoglycosides, imipenem and meropenem for production of a class B carbapenem-hydrolyzing enzyme.

C. indologenes is usually susceptible to piperacillin alone or combined with tazobactam, ceftazidime, cefepime, fluoroquinolones, rifampin and cotrimoxazole, but the in vitro susceptibility to these antibiotics should be systematically tested.

Antimicrobial susceptibility data on Chryseobacterium spp. remain very limited because this pathogen has rarely been isolated from clinical specimens. The results of the evaluation of a worldwide collection indicate that the newer quinolones (garenoxacin, gatifloxacin, and levofloxacin) may represent the most appropriate antimicrobial agents to treat infections caused by this pathogen. Garenoxacin was the most active quinolone (minimum inhibitory concentration required to inhibit the growth of $50 \%$ of organisms (MIC50): $0.12 \mu \mathrm{g} / \mathrm{mL}$ ); gatifloxacin (MIC50: $0.25 \mu \mathrm{g} / \mathrm{mL}$ ) and levofloxacin (MIC50: $0.5 \mu \mathrm{g} / \mathrm{mL}$ ) also inhibited $98.0 \%$ of the isolates, and the rate of susceptibility to ciprofloxacin (MIC50: $0.5 \mu \mathrm{g} / \mathrm{mL}$ ) was significantly lower. Trimethoprim-sulfamethoxazole showed reasonable activity. Among the $\beta$-lactams, the most active agents overall were piperacillin-tazobactam (MIC50: $4 \mu \mathrm{g} / \mathrm{mL}$; 80.0\% susceptibility), piperacillin (MIC50: $8 \mu \mathrm{g} / \mathrm{mL} ; 74.0 \%$ susceptibility), and cefepime (MIC50: $8 \mu \mathrm{g} / \mathrm{mL} ; 62.0 \%$ susceptibility). The carbapenems ( $6 \%$ to $12 \%$ susceptible) and the aminoglycosides ( $8 \%$ to $14 \%$ susceptible) exhibited poor activity against these pathogens [14].

\section{Conclusion}

C. indologenes should be considered as a potential pathogen in newborns in the presence of invasive equipment or on treatment with long-term broad-spectrum antibiotics. Appropriate choice of effective antimicrobial agents for treatment is difficult because of the unpredictability and 
breadth of antimicrobial resistance of these organisms, which often involves resistance to many of the antibiotics chosen empirically for serious Gram-negative infections.

\section{Consent}

Written informed consent was obtained from the parents of the patient for publication of this case report and any accompanying images. A copy of the written consent is available for review by the Editor-in-Chief of this journal.

\section{Authors' contributions}

GC and EG were the physicians in charge of our patient throughout his hospitalization and made substantial contributions to conception, acquisition, analysis and interpretation of data and drafting the manuscript. $P R$ and EGG helped to draft the manuscript. MR and AL were involved in revising the manuscript and final approval of the version. All authors read and approved the final manuscript.

\section{Competing interests}

The authors declare that they have no competing interests.

Received: 22 September 2009 Accepted: 14 January 2011

Published: 14 January 2011

\section{References}

1. Murray PR, Pfaller MA, Tenover FC, Yolken RH: Manual of Clinical Microbiology. 6 edition. Washington, DC: ASM Press; 1995, 528-530

2. Mandell GL, Dolin R: Principles and Practice of Infective Disease. 6 edition. New York: Elsevier; 2005, 2757-2759.

3. Du Moulin GC: Airway colonization by Flavobacterium in an intensive care unit. J Clin Microbiol 1979, 10:155-160.

4. Nulens E, Bussels B, Bols A, Gordts B, Van Landuyt HW: Recurrent bacteremia by Chryseobacterium indologenes in an oncology patient with a totally implanted intravenous device. Clin Microbiol Infect 2001, 7:391-393.

5. Lin JG, Wang WS, Yen CC, Liu JH, Chiou TJ, Yang MH, Chao TC, Chen PM: Chryseobacterium indologenes bacteremia in a bone marrow transplant recipient with chronic graft-versus-host disease. Scand J Infect Dis 2003, 35:882-883.

6. Bloch KC, Nadarajah R, Jacobs R: Chryseobacterium meningosepticum: an emerging pathogen among immunocompromised adults. Report of 6 cases and literature review. Medicine (Baltimore) 1997, 76:30-41.

7. Lu PC, Chan JC: Flavobacterium indologenes keratitis. Ophthalmologica 1997, 211:98-100.

8. Christakis GB, Perlorentzou SP, Chalkiopoulou I, Athanasiou A, Legakis NJ: Chryseobacterium indologenes non-catheter-related bacteremia in a patient with a solid tumor. J Clin Microbiol 2005, 43:2021-2023.

9. Hsueh PR, Teng LJ, Ho SW, Hsieh WC, Luh KT: Clinical and microbiological characteristics of Flavobacterium indologenes infections associated with indwelling devices. J Clin Microbiol 1996, 34(Suppl A):1908-1913.

10. Hsueh PR, Hsiue TR, Wu JJ, Teng LJ, Ho SW, Hsieh WC, Luh KT: Flavobacterium indologenes bacteremia: clinical and microbiological characteristics. Clin Infect Dis 1996, 23(Suppl B):550-555.

11. Cascio A, Stassi G, Costa GB, Crisafulli G, Rulli I, Ruggeri C, laria C: Chryseobacterium indologenes bacteraemia in a diabetic child. J Med Microbiol 2005, 54:677-680

12. Bayraktar MR, Aktas E, Ersay Y, Cicek A, Durmaz R: Postoperative Chryseobacterium indologenes bloodstream infection caused by contamination of distillate water. Infect Control Hosp Epidemiol 2007, 28:368-369.

13. Al-Tatari $\mathrm{H}$, Asmar Bl, Ang JY: Lumboperitoneal shunt infection due to Chryseobacterium indologenes. Pediatr Infect Dis J 2007, 26:657-659.

14. Kirby JT, Sader HS, Walsh TR, Jones RN: Antimicrobial susceptibility and epidemiology of a worldwide collection of Chryseobacterium spp.: report from the SENTRY Antimicrobial Surveillance Program (1997-2001). J Clin Microbiol 2004, 42:445-448. doi:10.1186/1752-1947-5-10

Cite this article as: Calderón et al:: Chryseobacterium indologenes infection in a newborn: a case report. Journal of Medical Case Reports 2011 5:10.

\section{Submit your next manuscript to BioMed Central and take full advantage of:}

- Convenient online submission

- Thorough peer review

- No space constraints or color figure charges

- Immediate publication on acceptance

- Inclusion in PubMed, CAS, Scopus and Google Scholar

- Research which is freely available for redistribution 